\title{
Pengaruh Mutu Pelayanan, Harga dan Promosi terhadap Kepuasan Konsumen di BC Street Coffee Denpasar
}

\author{
I MADE PUTRA AKEN MERTHAYASA, \\ I NYOMAN GEDE USTRIYANA, IGA.A LIES ANGRENI \\ Program Studi Agribisnis Fakultas Pertanian Universitas Udayana \\ Jl. PB. Sudirman Denpasar 80232 \\ Email: I.made.putra.aken@gmail.com \\ gede_ustriyana@unud.ac.id
}

\section{Abstract \\ The Impact of the Quality of Services, Price and Promotion on the Consumer Satisfaction at BC Street Coffee Denpasar}

The annual increase in the contribution made by the trading sector and hotel and restaurant sector has caused the restaurants in Denpasar, including the BC Street Coffee, to be getting more competitive. It is necessary to analyze the factors, such as the quality of services, price and promotion, which contribute to the consumer satisfaction. This current study is intended to identify the characteristics of the respondents, the quality of services, price and promotion on the consumer satisfaction. The study was conducted from March to May 2018. The respondents totaled 50. The data were analyzed using the validity test, reliability test, multiple linier analysis, classic assumption test, hypothesis test, and descriptive analysis. The dominant consumers of the BC Street Coffee were from 18 to 25 years old, male, senior high school graduates, private employees and single. They felt highly satisfied with the quality of services, price and promotion provided. Partially and simultaneously, the quality of services, price and promotion significantly contributed to the consumer satisfaction. The R Square showed that the quality of services, price and promotion contributed to the consumer satisfaction by $62 \%$, and the rest, namely $38 \%$, was affected by the other variables. It is suggested that the BC Street Coffee should always pay attention to what is desired and needed by the consumers and the price of the product offered. It is suggested to the future researchers that they add other variables and another object under a particular territory.

Keywords: quality of services, price, promotion, consumer satisfaction

\section{Pendahuluan}

\subsection{Latar Belakang}

Kota Denpasar bertumpu pada industri pariwisata yang menyebabkan kontribusi ekonomi Kota Denpasar masih didominasi oleh sektor perdagangan, hotel dan restoran (sektor tersier). Nilai dan kontribusi sektor Perdagangan, Hotel \& Restoran terus mengalami peningkatan dalam PDRB tahun 2012 s.d 2014 Kota Denpasar yaitu pada tahun 2012 sebesar 40,02\%, pada tahun 2013 sebesar 40,03\% dan tahun 2014 sebesar 40,41\% (Badan Pusat Statistik, 2015). Peningkatan nilai kontribusi tersebut diikuti oleh ketatnya persaingan di dalam sektor restoran. Usaha restoran dalam memasarkan produknya mempunyai suatu tujuan, untuk mencapai dan meningkatkan keuntungan. 
Keuntungan ini harus diimbangi dengan kepuasan konsumen sehingga usaha dapat tumbuh dan berkembang. Usaha yang tidak berhasil dalam memberikan kepuasan kepada konsumen akan kalah dalam persaingan dan menyebabkan usaha tersebut gulung tikar, jumlah restoran di Denpasar pada tahun 2012 sejumlah 76 dan 2013 sejumlah 72 mengalami penurunan dan pada tahun 2013 menuju 2015 mengalami peningkatan menjadi 449 dan pada tahun 2016 mengalami penurunan menjadi sejumlah 438 (Dinas Pariwisata Provinsi Bali, 2016 dalam atasiwirap, 2017). Jumlah restoran di Kota Denpasar tergolong fluktuatif, hal ini dapat disebabkan oleh restoran yang kalah dalam perasingan dan menyebabkan usaha tersebut gulung tikar karena tidak dapat memberikan kepuasan kepada konsumen.

BC Street Coffe merupakan salah satu café yang terlibat dalam persaingan dikota Denpasar. Pengusaha harus mengetahui faktor-faktor yang mempengaruhi kepuasan pelanggannya agar dapat melakukan perbaikan dan inovasi yang diharapkan dapat meningkatkan kepuasan pelanggan setelah melakukan transaksi di café BC Street Coffee. Faktor-faktor yang mempengaruhi kepuasan pelanggan seperti mutu pelayanan, harga dan promosi pada Café BC Street Coffee perlu di analisis agar dapat bertahan dalam persaingan dan menciptakan kepuasan bagi konsumen secara optimal serta dapat mengetahui seberapa besar pengaruhnya terhadap kepuasan konsumen.

\subsection{Rumusan Masalah}

Berdasarkan paparan latar belakang di atas dapat dirumuskan rumusan masalah sebagai berikut:

1. Bagaimana karakteristik konsumen BC Street Coffee?

2. Bagaimana mutu pelayanan, harga, dan promosi pada BC Street Coffee?

3. Bagaimana pengaruh mutu pelayanan, harga, dan promosi terhadap kepuasan konsumen?

\subsection{Tujuan Penelitian}

Berdasarkan rumusan masalah, maka tujuan penelitian ini adalah:

1. Menganalisis karakteristik konsumen BC Street Coffee.

2. Mengidentifikasi mutu pelayanan, harga, dan promosi pada BC Street Coffee.

3. Menganalisis pengaruh mutu pelayanan, harga, dan promosi terhadap kepuasan konsumen.

\section{Metode Penelitian}

\subsection{Lokasi dan Waktu Penelitian}

Penelitian ini dilakukan di Café BC Street Coffee yang beralamat di Jl. Teuku Umar No.15, Pemecutan Kelod, Denpasar Barat. Kota Denpasar. Dasar pertimbangan pemilihan lokasi adalah BC Street Coffee merupakan usaha yang telah berdiri selama enam tahun yaitu pada tahun 2012 hingga tahun 2018 dan telah memiliki banyak pesaing dalam usaha dibidang sejenis. Lokasi penelitian ini ditentukan secara purposive yaitu penelitian yang dilakukan secara sengaja dan terencana.Penelitian ini dilakukan pada bulan Maret sampai dengan Mei 2018.

\subsection{Data, Metode Pengumpulan Data, Metode Analisis Data}

Jenisdata yang dikumpulkan untuk penelitian ini adalah data kuantitatif dan kualitatif. Data kuantitatif yang digunakan berupa hasil wawancara dengan menggunakan kuesioner kepada responden dan data kualitatif yang digunakan dalam 
penelitian ini mencakup gambaran umum tempat penelitian serta karakteristik responden. Sumber data yang digunakan dalam penelitian ini adalah data primer dan data sekunder. Data primer meliputi data yang dikumpulkan dari hasil wawancara dengan memberikan daftar pernyataan atau kuisioner yang akan dinilai oleh responden dan data sekunder meliputi jurnal, artikel online, buku, dokumentasi kegiatan, ataupun catatan yang berhubungan dengan masalah yang di teliti. Responden dalam penelitian ini adalah konsumen yang telah berbelanja di BC Street Coffe dengan frekuensi belanja ditetapkan $\geq 2$ kali kunjungan, jumlah sample yang di tentukan secara purposive (sengaja) yaitu 50 orang responden. Metode yang di pergunakan dalam memperoleh data pada penelitian ini adalah wawancara, Observasi dan studi pustaka. Wawancara dilakukan untuk mengetahui gambaran umum usaha yang dijalankan dan wawancara melalui instrument kuisioner pada responden dilaksanakan melalui metode skala likert selanjutnya observasi dilakukan dengan mengadakan pengamatan langsung terhadap berbagai kegiatan yang sedang berlangsung pada objek yang diteliti yang terkahir Studi pustaka pengumpulan data ini menggunakan beberapa dokumen acuan, diantaranya dokumen-dokumen, buku-buku, literature yang berkaitan dengan materi penelitian pengaruh mutu pelayanan, harga, dan promosi terhadap kepuasan konsumen BC Street Coffee. Metode analis data yang digunakan sebagai berikut.

1. Uji validitas

Validitas atau kesahihan merupakan suatu ukuran yang menunjukkan tingkattingkat kevalidan atau kesahan suatu instrumen Rumus yang adalah digunakan sebagai berikut.

$$
T_{\text {nit }} \quad-\frac{n\left(\sum X\right)-\left(\sum X\right)\left(\sum Y\right)}{\sqrt{\left\{n\left(\sum X^{2}\right)-\left(\sum X\right)^{2}\right\}\left\{n\left(\sum Y^{2}\right)-\left(\sum Y\right)^{2}\right\}}}
$$

Keterangan:

$\mathrm{n} \quad=$ Jumlah responden

$\mathrm{X} \quad=$ Jumlah skor item (jawaban responden)

$\mathrm{Y} \quad=$ Jumlah skor total

Dalam penelitian ini menggunakan cara membandingkan nilai $r$ hitung dengan $r$ tabel koefisien korelasi product moment $>$ r-tabel $(\alpha ; n-2)$. Jumlah sampel dalam penelitian ini dilambangkan sebagai $\mathrm{n}$.

\section{Uji reliabilitas}

Reliabilitas adalah suatu instrument dapat dipercaya untuk digunakan sebagia alat pengumpul data karena instrument tersebut sudah baik. Instrumen yang baik tidak bersifat tendensius atau mengarahkan responden untuk memilih jawaban-jawaban tertentu. Instrumen yang sudah dapat dipercaya atau reliabel menghasilkan data yang dapat dipercaya. Apabila datanya benar sesuai dengan kenyataan, maka berapa kalipun diambil, hasilnya tetap. Konstruk atau variabel dikatakan reliabel jika memberikan nilai Cronbach Alpha $\geq 0,60$.

3. Analisis Regresi linier Berganda

Analisis regresi digunakan untuk mengetahui pengaruh antara variabel bebas (independent)dengan variabel terikat (dependent) yaitu antara Mutu pelayanan (X1 ),harga (X2 ) dan promosi (X3) terhadap kepuasan konsumen (Y). Data yang dianalisis menggunakan program komputer yaitu program SPSS. Rumus regresi linier berganda. 
Keterangan:

$$
Y=u+b_{1} X_{1}+b_{2} X_{2}+b_{3} X_{3}
$$

Y

$\mathrm{X} 1$

$\mathrm{X} 2$

$\mathrm{X} 3$

a, $b_{1}, b_{2}, b_{3}$

$$
\begin{aligned}
& =\text { tanggapan kepuasan konsumen } \\
& =\text { tanggapan mutu pelayanan } \\
& =\text { tanggapan harga } \\
& =\text { tanggapan promosi } \\
& =\text { konstanta }
\end{aligned}
$$

\section{Uji Normalitas}

Tujuan dari uji normalitas adalah untuk menentukan apakah variabel berdistribusi normal atau tidak. Model regresi yang baik adalah memiliki distribusi data normal atau mendekati normal. Pengujian normalitas dapatdilihat dari grafik normal probability plot, jika variabel berdistribusi normal, maka penyebaran plot akan berada disekitar dan disepanjang garis $45^{\circ}$. (Ghozali, 2006).

\section{Uji Multikolinieritas}

Multikolinieritas adalah penyimpangan model klasik dalam model regresi yang dihasilkan. Uji ini ditujukan untuk menguji apakah dalam model regresi adanya korelasi antara variabel independen. Mendeteksi ada tidaknya multikolinieritas dengan melihat Varience Inflance Factor (VIF). Jika VIF $<10$ dan nilai tolerance $>10 \%$ maka tidak terjadi multikolinieritas antara variabel bebas.

\section{Uji Heteroskedastisitas}

Uji heteroskedastisitas bertujuan untuk menguji apakah dalam model regresi terjadi ketidaksamaan varience dari residual satu pengamatan kepengamatan lainnya. Pendeteksian ada tidaknya heteroskedastisitas dilakukan dengan menggunakan grafik plot antara nilai prediksi variabel terikat (ZPRED) dengan residualnya (SRESID). Cara menganalisis asumsi Heteroskedastisitas dengan melihat grafik scatter plot.

\section{Uji Parsial (Uji t)}

Uji t parsial digunakan untuk mengetahui pengaruh masing-masing variabel independen secara parsial. Kaidah pengambilan keputusan dalam uji-t dengan menggunakan SPSS adalah:

a. Jika nilai signifikansi $>0,05$, maka Ho diterima dan Ha ditolak.

b. Jika nilai signifikansi $<0,05$, maka Ho ditolak dan Ha diterima.

8. Uji Simultan (Uji F)

Uji $\mathrm{F}$ dilakukan secara serentak untuk membuktikan hipotesis awal tentang pengaruh variabel harga (X1), kualitas pelayanan (X2), promosi (X3) secara simultanberpengaruh terhadap kepuasan konsumen (Y) sebagai variabel terikat. Hipotesis yang dapat diajukan untuk uji $\mathrm{F}$ adalah sebagai berikut.

a. Jika probabilitas $>0,05$, maka Ho diterima dan Ha ditolak

b. Jika probabilitas < 0,05, maka Ho ditolak dan Ha diterima

9. Uji Koefisien Determinasi $\left(R^{2}\right)$

Uji koefisien determinasi $\left(\mathrm{R}^{2}\right)$ merupakan pengujian untuk mengetahui berapa besar persentase sumbangan variabel independen terhadap variasi (naik-turunnya) variabel dipenden. Nilai $\mathrm{R}^{2}$ mempunyai interval antara 0 sampai 1 . Interprestasi dari nilai interval tersebut yaitu semakin besar nilai $\mathrm{R}^{2}$ (mendekati satu), maka semakin baik hasil untuk model regresi tersebut. Semakin mendekati nol, maka variabel independen secara keseluruhan tidak dapat menjelaskan variabel dipenden. Peneliti akan 
menguraikan secara rinci jawaban responden yang dikelompokan dalam kategori skor dengan menggunakan rentang skala sebagai berikut ( Husein Umar, 2005).

Maka interval dari kriteria rata- rata dapat di lihat sebagi berikut.

$\begin{array}{ll}\text { Tidak Puas (TP) } & : 50-90 \\ \text { Kurang Puas (KP) } & : 91-130 \\ \text { Cukup Puas (CP) } & : 131-170 \\ \text { Puas (P) } & : 171-210 \\ \text { Sangat Puas (SP) } & : 211-250\end{array}$

\section{Hasil dan Pembahasan}

\subsection{Karakteristik Responden}

Responden dalam penelitian ini adalah konsumen yang telah berbelanja di BC Street Coffe dengan frekuensi belanja ditetapkan $\geq 2$ kali kunjungan. Hasil karakteristik responden BC Street Coffee adalah konsumen berusia 18-25 tahun sebanyak 84\% mendominasi dan menunjukan sebagian konsumen adalah kategori remaja, remaja menjadikan BC Street Coffee sebagai tempat bertemu dan bertukar pikiran dengan teman, konsumen berjenis kelamin pria sebanyak $66 \%$ mendimonasi yang dapat diartikan bahwa sebagian besar konsumen BC Street Coffe adalah seorang pria, konsumen yang mimiliki pendidikan SMA sebanyak $60 \%$ mendominasi dengan demikian dapat di simpulkan bahwa konsumen yang berkunjung di BC Street Coffee adalah mereka yang mempunyai tingkat pendidikan relative tinggi, konsumen yang bekerja sebagai pegawai swasta yang mendominasi yaitu 56\% dapat di artikan bahwa responden yang bekerja sebagai pegawai swata melepepas kepenatan setelah bekerja seharian dengan cara mengunjungi BC Street Coffee, konsumen yang belum menikah mendominasi yaitu 92\% dapat dartikan bahwa konsumen yang berkunjung belum memiliki tanggung jawab dalam berumah tangga.

\subsection{Deskriptif Variabel Penelitian}

Rata - rata skor jawaban responden untuk variabel mutu pelayanan adalah 213.9 berada pada kategori sangat puas (211-250) dapat dikatakan konsumen BC Street Coffee sangat puas terhadap keseluruhan parameter variabel mutu pelayanan. Parameter dengan nilai skor tertinggi yaitu 225 terdapat pada parameter karyawan ramah dan murah senyum terhadap setiap konsumen hal tersebut menjadi keuunggulan dari BC Street Coffe dikarenakan BC Street Coffee menerapkan kepada setiap karyawan untuk selalu ramah dan murah senyum terhadap konsumen yang berkunjung, BC Street Coffee juga perlu memperhatikan nilai skor terendah yaitu 200 pada parameter karyawan mengerti keinginan dan kebutuhan konsumen hal tersebut perlu di perhatikan karena dapat mempengaruhi tingkat kepuasan konsumen terhadap mutu pelayanan di BC Street Coffee.

Rata- rata skor jawaban responden untuk variabel harga adalah 221 berada pada kategori sangat puas (211-250) dapat dikatakan konsumen BC Street Coffee sangat puas terhadap keseluruhan parameter variabel harga. Parameter dengan nilai skor tertinggi yaitu 224 pada parameter harga sesuai dengan manfaat yang diterima hal tersebut dikarenakan konsumen merasa telah mendapatkan manfaat yang dibutuhkan dari BC Street Coffee dengan setiap kebutuhan konsumen yang berbeda setiap orangnya. BC Street Coffee juga perlu memperhatikan nilai skor terendah yaitu 213 pada parameter harga yang terjangkau hal tersebut perlu di perhatikan BC Street Coffee agar lebih memperhatikan pada harga yang ditetapkan. Harga makanan yang terjangkau menjadi 
salah satu hal yang dapat menarik perhatian konsumen, jika biaya yang dikeluarkan oleh konsumen sesuai dengan persepsi dan manfaatnya maka konsumen dapat merasa puas

Rata- rata skor jawaban responden untuk variabel promosi yaitu 216.5 berada pada kategori sangat puas (211-250) dapat dikatakan konsumen BC Street Coffee sangat puas terhadap keseluruhan parameter variabel promosi. Parameter dengan nilai skor tertinggi yaitu 224 pada parameter promosi yang diberikan berhasil menarik perhatian konsumen dikarenakan banyak konsumen yang sangat puas dengan acara - acara menarik dan positif yang di selenggarakan oleh BC Street Coffe. BC Street Coffee juga perlu memperhatikan nilai skor terendah yaitu 75 pada parameter promosi mengingatkan tempat yang perlu dikunjungi hal tersebut perlu di perhatikan karena promosi produk atau jasa membantu dengan cara terbaik untuk membangun hubungan dengan pelanggan, karena semua orang mencari kesepakatan terbaik yang mempunyai kesesuaian.

\subsection{Uji Normalitas}

Tujuan dari uji normalitas adalah untuk menentukan variabel berdistribusi normal atau tidak. Hasil analisis uji normalitas data dengan menggunakan SPSS, dapat dilihat pada grafik probability plop bahwa data menyebar disekitar garis diagonal dan mengikuti arah garis diagonal, maka model regresi memenuhi asumsi normalitas dan dapat dilihat pada gambar 1. grafikprobability plot sebagai berikut.

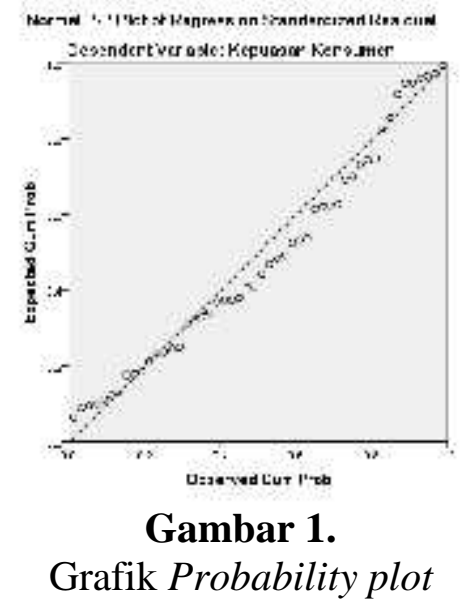

\subsection{Uji Multikolinieritas}

Hasil uji mulikolinieritas dalam model regresi tidak terjadi multikolinearitas atau korelasi yang sempurna antara variabel-variabel bebas, yaitu mutu pelayanan, harga dan promosi, karena telah memenuhi syarat yaitu nilai VIF lebih kecil dari 10 dan nilai toleranlebih besar dari 0,1 . Hasil pengitungan uji multikolinieritas melalui spss 22 dapat dilihat pada tabel 1. hasil uji multikolinieritas sebagai berikut.

Tabel 1.

Hasil Uji Multikolinieritas

\begin{tabular}{ccc}
\hline \multirow{2}{*}{ Model } & \multicolumn{2}{c}{ Colliniearity Statistic } \\
\cline { 2 - 3 } & Tolerance & VIF \\
\hline Mutu Pelayanan & 0,469 & 2,130 \\
Harga & 0,629 & 1,591
\end{tabular}




$\begin{array}{lll}\text { Promosi } \quad 0,612 & 1,635\end{array}$

Sumber: data primer yang diolah, 2018

\subsection{Uji Heteroskedastisitas}

Uji heteroskedastisitas bertujuan untuk menguji apakah dalam model regresi terjadi ketidaksamaan varience dari residual satu pengamatan kepengamatan lainnya. Grafik scatterplot menunjukan bahwa titik-titik menyebar secara acak serta tersebar baik di atas maupun dibawah angka nol pada sumbu, disimpulkan bahwa tidak terjadi heteroskedastisitas pada model regresi ini.Uji heteroskedastisitas dapat dilihat pada gambar 2 hasil uji heteroskedastisitas sebagai berikut.

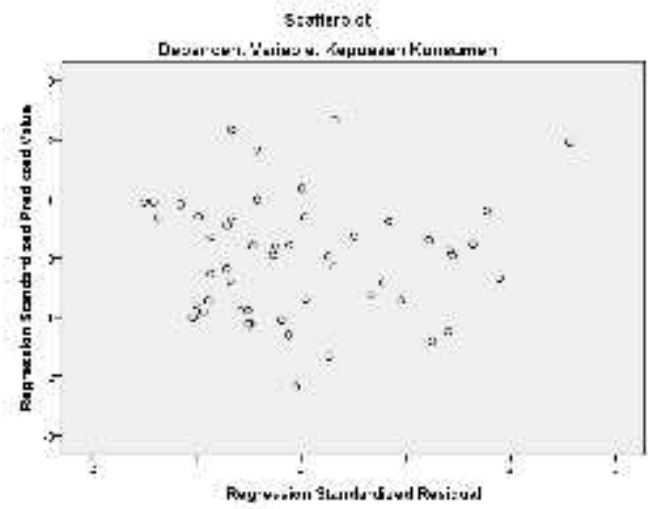

Gambar 2.

Grafik Scatterplot

\subsection{Analisis Regresi Linier Berganda}

Hasil analisis linier berganda antara mutu pelayanan (X1), Harga (X2), dan promosi (X3) terhadap Kepuasan konsumen (Y), yang dibantu dengan program spss 22. Hasil analisis linier berganda dapat dilihat pada tabel 2 hasil regresi linier berganda sebagai berikut.

Tabel 2.

Hasil Uji Regresi Linier Berganda

\begin{tabular}{ccccccc}
\hline \multirow{2}{*}{ Model } & \multicolumn{2}{c}{$\begin{array}{c}\text { Unstandardized } \\
\text { Coefficients }\end{array}$} & $\begin{array}{c}\text { Standardized } \\
\text { Coefficients }\end{array}$ & \multirow{2}{*}{$t$} & \multirow{2}{*}{ Sig. } \\
\cline { 2 - 4 } & $B$ & Std. Error & Beta & & \\
\hline Konstanta & 2,655 & 3,071 & & 0,865 & 0,392 \\
Mutu pelayanan & 0,245 & 0,089 & 0,367 & 2,750 & 0,008 \\
Harga & 0,462 & 0,184 & 0,289 & 2,510 & 0,016 \\
Promosi & 0,429 & 0,182 & 0,276 & 2,363 & 0,022 \\
\hline
\end{tabular}

Sumber data primer yang diolah, 2018

\subsection{Uji Parsial ( $t)$}

Uji t parsial digunakan untuk mengetahui pengaruh masing-masing variabel independen secara individual terhadap variabel dependent, agar mengetahui pengaruh yang ditimbulkan signifikan atau tidak. Hasil Uji t pengaruh mutu pelayanan,harga dan promosi terhadap kepuasan konsumen BC Street Coffe dapat dilihat pada tabel 2 sebagai berikut. 
1. Mutu pelayanan secara parsial berpengaruh yang signifikan terhadap kepuasan konsumen BC Street Coffee ditujukan dengan diperoleh nilai Sig mutu pelayanan 0,008 lebih kecil dari 0,05 jadi diperoleh kesimpulan bahwa H0 ditolak dan H1 diterima. Sesuai dengan penelitian yang dilakukan oleh Ari Susanto (2013) yang dalam penelitiannya menujukan kualitas pelayanan memiliki pengaruh yang signifikan terhadap kepuasan konsumen serta semakin baik kualitas pelayanan diyakini berpengaruh pada tingkat kepuasan konsumen. Perusahaan yang mengutamakan kualitas pelayanan yang baik akan memberikan dampak yang positif terhadap kepuasan konsumen (Walker, 2001).

2. Harga secara parsial berpengaruh yang signifikan terhadap kepuasan konsumen BC Street Coffee ditujukan dengan diperoleh nilai Sig 0,016 lebih kecil dari 0,05 jadi diperoleh kesimpulan H0 ditolak dan H1 diterima. Sesuai dengan penelitian yang dilakukan Oldy Ardhana (2010) yang dalam penelitiannya menunjukan harga memiliki pengaruh yang signifikan positif terhadap kepuasan konsumen. Harga merupakan pernyataan nilai dari sebuah produk. Nilai adalah perbandingan antara persepsi terhadap manfaat dengan biaya-biaya yang dikeluarkan untuk mendaptkan produk. Jika biaya yang dikeluarkan oleh konsumen sesuai dengan persepsi dan manfaatnya maka konsumen dapat merasa puas Tjiptono (2008).

3. Promosi secara parsial berpengaruh yang signifikan terhadap kepuasan konsumen BC Street Coffee ditujukan dengan diperoleh nilai Sig promosi 0,022 lebih kecil dari 0,05 jadi meperoleh kesimpulan $\mathrm{H} 0$ ditolak dan $\mathrm{H} 1$ diterima.Sesuai dengan penelitian yang dilakukan oleh Dendi Sumawan (2015) yang dalam penelitiannya menujukan promosi memiliki pengaruh yang signifikan terhadap kepuasan konsumen dan promosi produk atau jasa membantu dengan cara terbaik untuk membangun hubungan dengan pelanggan, karena semua orang mencari kesepakatan terbaik yang mempunyai kesesuaiian. Informasi produk dengan adanya potongan harga dan penawaran khusus lainnya pada produk dapat meningkatkan tingkat kepuasan pelanggan.

\subsection{Uji Simultan $(F)$}

Hasil penelitian yang telah diperoleh dan kemudian dilakukan analisis secara kuantitatif, menunjukkan bahwa pengaruh mutu pelayanan harga dan promosi secara bersama-sama (simultan) berpengaruh yang signifikan terhadap kepuasan konsumen BC Street Coffee. Hal ini ditunjukan dari nilai Sig 0,000 yang artinya lebih kecil dari 0,05. Hasil penelitian ini sesuai dengan hasil penelitian yang telah dilakukan oleh Arisandy (2016) yang dalam penelitiannya menunjukan bahwa mutu pelayanan, harga, dan promosi secara simultan memiliki pengaruh yang signifikan terhadap kepuasan konsumen.

\subsection{Uji Koefisien Determinasi}

Uji koefisien determinasi ( $R$ square) merupakan pengujian untuk mengetahui seberapa besar persentase sumbangan variabel independent terhadap variabel dependent. Hasil dari penelitian ini dapat dilihat pada tabel 3uji koefisien determinassebagai berikut.

Tabel 3.

Uji Koefisien Determinasi

\begin{tabular}{ccccc}
\hline Model & $R$ & $R$ Square & Adjusted $R$ Square & Std. Error of the Estimate \\
\hline 1 & 0,785 & 0,616 & 0,591 & 2,682 \\
\hline
\end{tabular}


Nilai dari koefisien determinasi ( $R$ square)sebesar 0,616. Besarnya angka koefisien determinasi ( $R$ square) sebesar 0,616 sama dengan 62\%. Angka tersebut mengandung makna bahwa variabel mutu pelayanan, harga, dan promosi dapat menerangkan kepuasan konsumen sebesar 62\% dan sisanya sebesar 38\% dipengaruhi variabel lain diluar model regresi dalam penelitian ini.

\section{Simpulan dan Saran}

\subsection{Simpulan}

Simpulan dari hasil penelitian mengenai pengaruh mutu pelayanan harga dan promosi terhadap kepuasan konsumen BC Street Coffee sebagai berikut.

1. Responden dalam penelitian ini adalah konsumen yang telah berbelanja di BC Street Coffe dengan frekuensi belanja ditetapkan $\geq 2$ kali kunjungan, diperoleh hasil karakteristik konsumen BC Street Coffee adalah konsumen yang berusia 1825 tahun remaja yang menjadikan BC Street Coffee sebagai tren Life style, berjenis kelamin pria, memiliki pendidikan relative tinggi yaitu SMA, bekerja sebagai pegawai swasta yang melepas kepenatan di BC Street dan belum memiliki tanggung jawab dalam berumah tangga atau belum menikah mendominasi sebagai konsumen BC Street Coffee.

2. Rata- rata skor nilai tanggapan terhadap variabel mutu pelayanan adalah $(213,9)$, variabel harga adalah (221) dan variabel promosi yaitu $(216,5)$ ketiga variabel termasuk pada ketegori sangat puas (211-250).Konsumen pada BC Street Coffee sudah merasa sangat puas terhadap kinerja ketiga variabel tersebut.

3. Pengaruh variabel mutu pelayanan, harga dan promosi secara parsial memiliki pengaruh yang signifikan terhadap variabel kepuasan konsumen BC Street Coffee. Variabel mutu pelayanan, harga, dan promosi secara simultan memiliki pengaruh yang signifikan terhadap kepuasan konsumen BC Street Coffee. Koefisien determinasi ( $R$ Square)mutu pelayanan, harga, dan promosi dapat menerangkan kepuasan konsumen sebesar $62 \%$ dan sisanya sebesar $38 \%$ dipengaruhi variabel lain diluar model regresi in

\subsection{Saran}

Berdasarkan simpulan yang diperoleh, maka peneliti memberikan saran sebagai berikut:

1. BC Street Coffee diharapkan selalu memperhatikan keiinginan dan kebutuhan konsumen sehingga BC Street Coffee dapat menerapkan kebijakan yang tepat dalam meningkatkan kepuasan konsumen.

2. BC Street Coffee agar selalu memperhatikan harga produk yang ditawarkan sehingga produk yang dijual selalu terjangkau bagi konsumen dan BC Street Coffee dapat bersaing dengan bisnis yang sejenis dengan menrapkan harga yang terjangkau dengan kualitas produk yang baik agar konsumen selalu merasa puas terhadap harga yang ditawarkan.

3. Bagi peneliti selanjutnya yang ingin mengembangkan penelitian ini disarankan untuk merubah atau menambahkan jumlah variabel dalam perhitungan. Peneliti juga menyarankan dalam penelitian selanjutnya agar menambah jumlah café atau objek yang di teliti agar mencakup satu daerah tertentu.

\section{Ucapan Terimakasih}


Bapak Rifka Amanda selaku pemiliki BC Street Coffee yang sudah memberikan izin untuk peneliti melakukan penelitian di usaha yang dimilikiserta memberikan informasi tentang gambaran umum usahayang dimiliki, para pegawai BC Street Coffee yang telah membantu dan memberikan tambahan mengenai gambaran umum usaha yang dijalankan BC Street Coffee, dan konsumen BC Street Coffee yang telah menjadi responden dalam penelitian ini.

\section{Daftar Pustaka}

Ardhana, Oldhy. 2010. Analisis Pengaruh Kualitas Pelayanan, Harga dan Lokasi Terhadap Kepuasan Pelanggan. Skripsi pda Fakultas Ekonomi Universitas Diponogoro Semarang

Arisandy, Devy. 2016. Pengaruh Mutu Pelayanan, Harga dan Promosi Terhadap Kepuasan Konsumen Di Coffee Toffee Bogor. Skripsi pada Fakultas Ekonomi Dan Manajemen Institut Pertanian Bogor. Bogor.

Atasiwirap. 2017. Jumlah Restoran / Rumah makan di Denpasar tahun 2010 - 2014.

Pariwisata denpasarkota.go.id. Diakses pada tanggal 19 November 2017

Bagyono.2014.Pariwisata dan Perhotelan,Bandung: Alfabeta

BPS. 2015.Bali dalam Angka 2015. BPS Denpasar.

Ghozali, Imam. 2006. Aplikasi Analisis Multivariate dengan Program SPSS. Semarang :Badan Penerbit Undip.

Sumawan, Dendi.2015. Analisis Pengaruh Promosi, Harga dan Lokasi terhadap Kepuasan Konsumen Pelanggan Soto Kudus Kauman, Pondok Cabe Kota Tanggerang Selatan).Fakultas Ekonomi dan Bisnis Universitas Islam Negeri Syarif Hidayatullah Jakarta.

Susanto, Ari.2013. Pengaruh Harga, Kualitas Pelayanan dan Nilai Pelanggan terhadap Kepuasan Konsumen pada Rumah Makan di Kota Purwokerto.Fakultas Ekonomi. Universitas Negri Semarang

Tjiptono, Fandy. 2004. Perspektif Manajemen dan Pemasaran Kontemporer. Yogyakarta: Andi.

Walker. 2001. Managing Customer Dissatisfaction Through Effective Complaint Management System. Journal of Management Strategy. 